\title{
Basic School Pupils' Attitude towards the Use of BridgeIT Mobile Application for Learning Mathematics
}

Nasrudeen Ayinde Malik

Bakre Disu Oshodi Memorial High School, Nigeria, maliknasrudeen@gmail.com

Medinat Folorunso Salman

Department of Science Education, Faculty of Education, University of Ilorin, Ilorin, Nigeria, salman_mf2005@yahoo.com

\section{Khadijat S. Ameen}

Department of Science Education, Faculty of Education, University of Ilorin, Ilorin, Nigeria, ameen.sk@unilorin.edu.ng

\section{Kehinde Abdullahi}

Department of Science Education, Faculty of Education, University of Ilorin, Ilorin, Nigeria, k.abdullah2004@yahoo.com

\footnotetext{
The problems of pupils' understanding, performance and attitude towards mathematics cannot be overlooked. This study investigated the basic school pupils' attitude towards the use of BridgeIT mobile application for learning mathematics in Lagos State, Nigeria. The study was a descriptive research of a survey method. A simple random sampling technique was used to select 1,310 from 13,100 pupils from the 131 schools using BridgeIT in Lagos State. The researchers designed questionnaire, validated by two mathematics teachers from BridgeIT schools, three mathematics educators and one educational technology was used for collecting data. The questionnaire reliability index was 0.76 obtained with the use of Guttmann Split half procedure. The two research questions raised were answered using percentages while the hypothesis generated was tested using Mann-Whitney $U$ test at 0.05 level of significance. Findings of the study showed that the pupils' attitude towards the use of BridgeIT mobile application for learning was positive with $89 \%$. Also, no significant difference in the attitude of pupils based on gender. Based on the findings, it was recommended that the use of BridgeIT mobile application for learning should be extended to other states and possibly to other nations.
}

Keywords: attitude, bridgeit, mobile application, basic school, learning mathematics, attitude

\section{INTRODUCTION}

Mathematics is a subject that prepares an individual for academic excellence and useful living in the society. Any society that is preparing an individual for useful living must develop a strong Mathematical foundation at the basic school level. Malik and Salman (2018) expressed that Mathematics is a concenter subject which serves as foundation for pupils' level of thinking, skill development and problem solving. Malik (2017) opined that Mathematics is a unifying subject that prepares pupils for a useful and meaningful living and that Mathematics is a language and key to everyday activities of mankind in science and technology.

Citation: Malik, N. A., Salman, M. D., Ameen, K. S. \& Abdullahi, K. (2020). Basic Schools Pupils' Attitude towards the Use of BridgeIT Mobile Application for Learning Mathematics. Anatolian Journal of Education, 5(2), 131-142. https://doi.org/10.29333/aje.2020.5211a 
Mathematics embraces many important ideas about numbers and space which involves problemsolving activities and a very powerful way of communication. Akanmu (2017) asserted that Mathematics is the study of numbers, symbols, counting, measuring, number patterns and relationships of quantities. Nneji and Alio (2017) observed that Mathematics as a subject does not only deal with manipulation of numbers, but also goes further to explain relationships between the numbers, attributes of the number and application of the numbers to solving day to day practical life problems. Imoko and Isa (2015) posited that Mathematics provides the bedrock and foundation for creative thinking and cognitive development and should, therefore, be emphasised early in the academic life of the nation's citizenry.

Abdulhamid, Abubakar and Tela (2017) expressed that teaching Mathematics requires application of effective methods that will bring active learning, but the absence of this will make the pupils not to participate actively in Mathematics class. National Open University of Nigeria (NOUN) (2012) emphasized that teaching objectives in mathematics at primary school level has been that pupils memorise facts and acquire skills in calculating and manipulating numbers. Also, teachers emphasise skill in mastery of understanding of ideas, operations and application of knowledge through technology for effective learning. Olive and Makar (2010) examined the effect of technology on the nature of mathematical knowledge by arguing that, mathematics to be a static body of knowledge to be learned, it means that the role of technology in this process would be primarily that of an efficiency tool. This will help the pupils to learn mathematics more efficiently. It was further argued that mathematical knowledge and mathematical practices are inseparably linked, and the connection can be supported using technologies.

The basic school education holds a sturdy base in the educational system of Nigeria that is hopeful for scientific and technological advancement. National Teachers' Institute (NTI) (2000) asserted that primary (basic) education gives the necessary preparation for secondary education. In essence, the basic Mathematics teaching will lay the foundation of such children's future in advanced studies in Mathematics as well as in other school subjects that requires the use of Mathematics. Based on this, Salman (2009) posited that basic education forms the building blocks for further studies in mathematics. That is, it provides a head start that determines the subsequent development profiles of technology and society. Therefore, the goals of Mathematics teaching and learning at the basic school level as stated in NTI (2000) are to help children develop their abilities in the use of mathematical ideas in their daily-life activities; help children develop positive attitude to the learning of mathematics; help children develop logical thinking; help children to acquire basic knowledge and skills in numbers, quantities and geometrical figures; and provide a solid foundation for further learning of mathematics.

Ayotola and Ishola (2013) affirmed that the incessant low performance of pupils in primary mathematics and the reduction in the number of pupils who show interest in furthering their education up to higher institution in mathematics or mathematics-related courses call for a closer look at how the subject is taught. However, Etuk, Maria, and Asukwo (2013) posited that the solid rock of education system lies on knowledgeable, competent, well-trained and devoted teachers. It was further stated that students' level of participation in the instructional process is critical. Also, the students' perception gives way to operational challenges. It was further opined that the way the students perceived knowledge and their attitude assist the teacher to change teaching strategies which will improve students' understanding.

The positive attitude on the part of the pupils is very important in the use of technology if it is to be effectively integrated into the basic school curriculum. Cherry (2015) defined attitude as learned tendency to evaluate things in certain ways, including people, issues, objects, and events. Such evaluations can be positive or negative but at times uncertain. Attitude was further classified into 
cognitive, affective, and behavioural components. Cognitive component consists of beliefs, affective component comprises of feelings and emotions, while behavioural component consists of actions and observational responses. Malik and Salman (2016) asserted that the use of technologies in teaching and learning of Mathematics will go a long way to improve the pupils' understanding of Mathematics and rate of failure will either reduce or be eradicated completely.

Pearson Foundation (2014) opined that for over a decade, BridgeIT has brought innovative and effective teaching practices to more than ten thousand educators in classrooms around the world. It was further explained that BridgeIT uses the latest mobile technology such as mobile phones to provide teachers with training and supports that help them enhance teaching, create a more studentcentered learning environment, and improve classroom culture. Therefore, BridgeIT pupils are more engaged and likely to attend class and show measurably increased learning gains.

In 2010, the Pearson Foundation and Nokia Corporation, in close partnership with the Lagos State Universal Basic Education Board (LASUBEB), agreed to launch BridgeIT mobile application in Nigeria. Soon thereafter this partnership approached Airtel Nigeria in order to provide delivery of video into the BridgeIT Schools. It was launched in order to make mathematics pleasurable, increase the understanding of the pupils' mathematics and to increase the academic performance of the pupils in mathematics (Pearson Foundation, 2011).

The BridgeIT project focused on capacity building of mathematics teachers, creating a system for integrating BridgeIT approaches into Nigerian Primary School classrooms to improve teacher performance, and to increase learning gains among basic 5 and 6 pupils in mathematics (Pearson Foundation, 2011). BridgeIT has trained more than 400 teachers in Nigeria on a wide range of topics, including using tools for lesson plan development methodology, the pedagogical foundation of the BridgeIT program, classroom simulation monitoring and evaluation outcomes and equipment troubleshooting techniques (Pearson Foundation, 2014). One of the purposes of the BridgeIT mobile application is Participatory Learning Environment (PLE) in which pupils are actively engaged in constructing and acquiring knowledge. It is where the pupils are participating in the classroom activities through group/pair work; pupils and teachers are engaging in dialogue, and the teachers act as facilitators of knowledge and interaction (Pearson Foundation, 2011).

International Youth Foundation (IYF) (2011) assessed learning outcomes for $5^{\text {th }}$ and $6^{\text {th }}$ graders students and the attitude of both the teachers and students in Tanzania on the introduction of technology, educational video and teachers support by BridgeIT. Findings revealed that students taught with BridgeIT mobile application performed academically well, with a positive attitude to the use of BridgeIT mobile application. Pearson Foundation (2012) evaluated the effectiveness of implementing BridgeIT mobile application contents in India. Findings revealed that teacher effectiveness improved by $13 \%$, teaching style changed on average from "telling" to "constructivism", and students took more active roles in the classroom and improved the students' academic performance by $10 \%$. Malik and Salman (2016) examined the effect of BridgeIT mobile application on middle basic school pupils' performance in Mathematics in Lagos State. Findings revealed that pupils performed positively in Mathematics when taught with BridgeIT mobile application and that there was no gender difference on the performance of both male and female pupils. Studies on pupils' attitude towards the use of BridgeIT mobile application for learning mathematics have not been carried out in Nigeria. Therefore, this study examined the basic school pupils' attitude towards the use of BridgeIT mobile application for learning mathematics in Lagos State, Nigeria.

\section{Research Questions}

Answers were sought to the following research questions in the study: 
1. What is the attitude of basic school pupils towards the use of BridgeIT mobile application for teaching mathematics?

2. Does basic school pupils' attitudes on the use of BridgelT mobile application for teaching mathematics vary based on their gender?

\section{Research Hypothesis}

Based on research question 2, the correspondence hypothesis was tested in this study:

$\mathrm{HO}_{1}$ : There is no significant difference in the attitude of pupils on the use of BridgeIT mobile application for teaching mathematics based on their gender.

\section{Literature Review}

Mobile application technology is an instrument for change and innovation. The educational value of technology was established by a variety of experiments. Pupils who use technology especially mobile application attained better results in communication, cooperation and solving problems (Williams, 2003). Graff (2003) claimed that technology supports the improvement of pupils' creative and mental activities. Creativity in the use of technology can increase creative thinking (Wheeler, Waite \& Bromfield, 2002). Using technologies contributed positively to the attitude of pupils towards learning (Neo, 2003). For instance, Haunsel and Hill (2002) found out that pupils using computers had a positive attitude than pupils who were educated by traditional style of teaching.

Attitudes have been posited to comprise affective, cognitive and behavioural components (Maio \& Haddock, 2010). In affective component, the feelings or emotions of an individual is associated with the object. While, cognitive component, is what the individual attitude thinks or believes in an object. The behavioral component is the tendency to act in a certain approach to the object. It has been realized that individual's attitude towards others, objects or situations may be favourable, unfavourable or ambivalent. Hence, pupils' attitude towards the use of technology for learning purposes could be positive, negative or ambivalent.

Saade and Galloway (2005) appreciated the relevance of attitudes towards the use of computer and other technologies devices for learning. Nayashi, Chen, Ryan, and Wu, (2004) asserted that pupils that have positive attitude to use technology for learning set to perform better than those with negative attitude. British Educational Communication and Technology Agency (BECTA) (2003) reported that negative attitude was a barrier towards integration of ICT in teaching and learning. While Rhoda and Gerald (2000) found that positive attitude towards ICT use is widely recognized as a necessary condition for effective computer use in teaching and learning. Odogwu and Mbah (2015) found that students had a positive attitude towards the use of ICT in learning mathematics. This positive attitude is an indicator of willingness for effective use of technology in learning mathematics. It, therefore, appears that pupils' attitude may have great influence on the adoption of technology for learning mathematics.

BridgeIT is a professional development program that uses familiar mobile technology to deliver educational content as well as training, allowing teachers to integrate innovative practice into the classrooms. Taking advantage of wireless networks that exist even in regions where physical materials and opportunities for collaborative are notoriously absent, the program is strategic and flexible, and has been successfully implemented in ten countries since its inception over a decade ago. For ten years, the Pearson Foundation, Nokia (now Microsoft) and others have joined with national and local communities worldwide to deliver a successful and innovative program that's changing how learning happens in remote areas around the globe. Combining content and technology with teacher training, BridgeIT is translating into measurable outcomes through its strong partnership model. Nokia was 
BridgeIT's global technology partner prior to the April 2014 acquisition by Microsoft. Since then, the great work initiated by Nokia in the area of mobile education was transferred to Microsoft together with the acquisition of Nokia's Devices and services business (Pearson Foundation, 2014).

Since 2003, BridgeIT has brought innovative and effective teaching practices to more than 15,000 educators, representing 10 countries across the globe. The program is a public-private partnership among national and regional governments, non-profits, corporative and other local stakeholders and communities. The Pearson Foundation and Nokia have been global partners supporting the effort, providing funding, program management, and pedagogy and technology expertise-and now, with its acquisition of Nokia in April 2014, Microsoft is taking on the lead as BridgeIT's global technology partner (Pearson Foundation, 2014). The program began in Philippines with the support of the International Youth Foundation and United Nations Development Program. The program continues to run in Philippines, and the following countries such as Bangladesh, Chile, Colombia, Haiti, India, Indonesia, Nigeria, South Africa and Tanzania (Pearson Foundation, 2014).

Nigeria provided training and resources to more than 400 teachers for grades five and six in 131 schools. It was launched in 2011. BridgeIT schools have experienced a high increase in enrolment of pupils when compared with none-BridgeIT schools. Lagos State Universal Basic Education Board (LASUBEB) (2015) reported that pupils are more punctual and have displayed significant improvement in attendance and academic performance in internal and external examinations. Teachers have developed more interest in the art of teaching and learning of mathematics through the use of technology. India in 3 years, BridgeIT has served more than 300 teachers and 11,000 grades-school students. Pre and Post BridgeIT evaluation indicated of good teaching (including criteria such as "asking probing questions", "checking in at least once with all students" and "making connections to prior knowledge") in observed classrooms jumped to 32 percent from an average of 10.13 percent. With a goal of improving student learning of $5^{\text {th }}$ and $6^{\text {th }}$ grades Mathematics, Science and English curricula, BridgeIT in India's first two years involved 160 teachers engaging more than 4,800 students. The programme had a positive and statistically significant impact on students learning for both disciplines, with BridgeIT students outgaining their peers in control schools by an average of 8 percent points in English and 15 percent points in Mathematics and Science.

\section{METHOD}

This study was a descriptive research of survey method, which involves the use of questionnaire for collecting data. The population for this study consists of all pupils in BridgeIT schools in Lagos State. In which 10 pupils in basic 5 from each of the 131 BridgeIT schools were randomly sampled, given a total of one thousand three hundred and ten pupils, that is, six hundred and three males and seven hundred and seven females.

The instrument used was a questionnaire on pupils' attitudes on the use of BridgeIT mobile application for learning mathematics. This instrument was adapted from the studies of Wafa' and Awatif (2009). In which, 18 items were selected considering their relevance to the pupils' attitudes to the use of the mobile application by their teachers for teaching mathematics. The pupils' questionnaire contained two sections, that is, sections A and B. Section A deals with pupils' personal information such as the name of the school and gender. Section B consists of information on pupils' attitudes to the use of BridgeIT mobile application for teaching mathematics, and it contained 17 items on which response mode for the items was based on Yes and No.

The research instrument was validated by two Mathematics teachers from BridgeIT schools, three Mathematics educators and one Educational Technology expert for face validity, using a checklist containing the following: 
(i) language clarity to the target population; and

(ii) relevance to the study.

The reliability of the instrument was determined by administering it twice with an interval of four weeks using the test-retest method. The instrument was administered to 655 pupils of BridgeIT schools that were not parts of the participating sample but have similar characteristics. Test re-test procedure was subjected to test using Guttmann split half and a reliability coefficient of 0.76 was obtained. This indicates that the test instrument "questionnaire" is reliable.

The researchers and three research assistants that were recruited administered copies of the questionnaire to 1310 pupils of the 131 BridgeIT schools, after seeking the consent of their teachers, and the parents of the pupils' through the signing of the consent forms. Only 1307 questionnaires were retrieved by the research assistants for data analysis. The researchers and research assistants administer the questionnaire to the pupils by putting them through on areas not clear to them and the questionnaire was collected immediately. Administering the questionnaire covered all the twenty Local Government Areas in Lagos State, Nigeria, and this took the researchers eight weeks. The data collected were analysed using descriptive and inferential statistics. The frequencies were converted to percentages to answer the research question 1, while research hypothesis was tested using MannWhitney U test.

\section{FINDINGS}

Research Question 1: What is the attitude of basic school pupils towards the use of BridgeIT mobile application for learning mathematics?

Table 1 shows the pupils attitudes towards the use of BridgeIT mobile application for teaching mathematics. Therefore, from the results it was observed that the pupils' attitude towards the use of BridgeIT mobile application was positive with $89 \%$ using the average percentage. 
Table 1

Basic school pupils' attitude towards the use of BridgeIT mobile application for teaching mathematics

\begin{tabular}{|c|c|c|c|c|c|}
\hline \multirow[t]{2}{*}{$\mathrm{S} / \mathrm{N}$} & \multirow[t]{2}{*}{ ITEMS } & \multicolumn{2}{|c|}{ YES } & \multicolumn{2}{|c|}{$\mathrm{NO}$} \\
\hline & & $\mathrm{F}$ & $\%$ & $\mathrm{~F}$ & $\%$ \\
\hline 1 & $\begin{array}{l}\text { Have you heard of BridgeIT mobile application before using it by your } \\
\text { teacher? }\end{array}$ & 367 & 28.1 & 940 & 71.9 \\
\hline 2 & $\begin{array}{l}\text { BridgeIT mobile application encourages me to change my attitude to learning } \\
\text { of Mathematics }\end{array}$ & 1291 & 98.8 & 16 & 1.2 \\
\hline 3 & $\begin{array}{l}\text { The use of BridgeIT mobile application by my teacher makes me think about } \\
\text { Mathematics }\end{array}$ & 1272 & 97.3 & 35 & 2.7 \\
\hline 4 & $\begin{array}{l}\text { I prefer using BridgeIT mobile application to } \\
\text { solve mathematics problems on my own }\end{array}$ & 1126 & 86.2 & 181 & 13.8 \\
\hline 5 & $\begin{array}{l}\text { I concentrate better when the teacher uses } \\
\text { BridgeIT mobile application to teach me } \\
\text { mathematics in the classroom }\end{array}$ & 1260 & 96.4 & 47 & 3.6 \\
\hline 6 & I prefer to learn mathematics through the use of BridgeIT mobile application & 1177 & 90.1 & 130 & 9.9 \\
\hline 7 & $\begin{array}{l}\text { BridgeIT mobile application is easy to use for } \\
\text { learning mathematics }\end{array}$ & 1272 & 97.3 & 35 & 2.7 \\
\hline 8 & $\begin{array}{l}\text { The use of BridgeIT mobile application will } \\
\text { make many pupils to pass mathematics }\end{array}$ & 1071 & 81.9 & 236 & 18.1 \\
\hline 9 & $\begin{array}{l}\text { Charging the BridgeIT mobile application } \\
\text { makes me angry when the teacher is using it to teach me }\end{array}$ & 313 & 23.9 & 994 & 76.1 \\
\hline 10 & $\begin{array}{l}\text { When the teacher uses BridgeIT mobile } \\
\text { application for teaching mathematics, it makes } \\
\text { it difficult for pupils to move around the } \\
\text { classroom }\end{array}$ & 658 & 50.3 & 649 & 49.7 \\
\hline 11 & $\begin{array}{l}\text { The use of BridgeIT mobile application for } \\
\text { teaching mathematics by my teacher save time } \\
\text { and effort }\end{array}$ & 1224 & 93.6 & 83 & 6.4 \\
\hline 12 & $\begin{array}{l}\text { Teacher talks less when using BridgeIT } \\
\text { mobile application to teach mathematics, hence I concentrate better in the } \\
\text { class }\end{array}$ & 1243 & 95.1 & 64 & 4.9 \\
\hline 13 & $\begin{array}{l}\text { Learning mathematics through the use of } \\
\text { BridgeIT mobile application has been a } \\
\text { pleasant experience }\end{array}$ & 1135 & 86.8 & 172 & 13.2 \\
\hline 14 & $\begin{array}{l}\text { Pupils concentrate more in learning mathematics When BridgeIT mobile } \\
\text { application is used Compared to use of social media }\end{array}$ & 1166 & 89.2 & 141 & 10.8 \\
\hline 15 & $\begin{array}{l}\text { I do not want to associate with BridgeIT } \\
\text { mobile application because it diverts my attention away from the class }\end{array}$ & 95 & 7.3 & 1212 & 92.7 \\
\hline 16 & $\begin{array}{l}\text { I am afraid of BridgeIT mobile } \\
\text { application equipment when installed }\end{array}$ & 131 & 10.0 & 1176 & 90.0 \\
\hline 17 & $\begin{array}{l}\text { I learn more and better mathematics from } \\
\text { BridgeIT mobile application than I do } \\
\text { from textbooks }\end{array}$ & 1134 & 86.8 & 173 & 13.2 \\
\hline
\end{tabular}

Research Question 2: Does basic school pupils' attitude towards the use of BridgeIT mobile application for teaching mathematics vary based on their gender?

Table 2 shows the basic school pupils' attitude towards the use of BridgeIT mobile application for teaching mathematics based on their gender. The results indicated that the pupils attitude does not vary based on their gender towards the use of BridgeIT mobile application for learning Mathematics based on the percentages of respondents. 
Table 2

Percentages of respondents on variation of pupils' attitude toward the use of BridgeIT mobile application for teaching mathematics across gender

\begin{tabular}{|c|c|c|c|c|c|c|c|c|c|}
\hline \multirow[t]{3}{*}{$\mathrm{S} / \mathrm{N}$} & \multirow[t]{3}{*}{ ITEMS } & \multicolumn{4}{|c|}{ YES } & \multicolumn{4}{|c|}{$\mathrm{NO}$} \\
\hline & & \multicolumn{2}{|c|}{ MALE } & \multicolumn{2}{|c|}{ FEMALE } & \multicolumn{2}{|c|}{ MALE } & \multicolumn{2}{|c|}{ FEMALE } \\
\hline & & F & $\%$ & $\mathrm{~F}$ & $\%$ & $\mathrm{~F}$ & $\%$ & F & $\%$ \\
\hline 1 & $\begin{array}{l}\text { Have you heard of BridgeIT mobile } \\
\text { application before using it by your } \\
\text { teacher? }\end{array}$ & 159 & 12.2 & 208 & 15.9 & 433 & 33.1 & 507 & 38.8 \\
\hline 2 & $\begin{array}{l}\text { BridgeIT mobile application } \\
\text { encourages me to learn mathematics }\end{array}$ & 585 & 44.8 & 706 & 54.0 & 6 & 0.5 & 10 & 0.8 \\
\hline 3 & $\begin{array}{l}\text { The use of BridgeIT mobile } \\
\text { application by my teacher makes } \\
\text { me think about mathematics }\end{array}$ & 575 & 44.0 & 697 & 53.3 & 17 & 1.3 & 18 & 1.4 \\
\hline 4 & $\begin{array}{l}\text { I prefer using BridgeIT mobile } \\
\text { application to solve mathematics } \\
\text { problems on my own }\end{array}$ & 494 & 37.8 & 632 & 48.4 & 97 & 7.4 & 84 & 6.4 \\
\hline 5 & $\begin{array}{l}\text { I concentrate better when the } \\
\text { teacher uses BridgeIT mobile } \\
\text { application to teach me mathematics } \\
\text { in the classroom }\end{array}$ & 570 & 43.6 & 690 & 52.8 & 22 & 1.7 & 25 & 1.9 \\
\hline 6 & $\begin{array}{l}\text { I prefer to learn mathematics through } \\
\text { the use of BridgeIT mobile application }\end{array}$ & 531 & 40.6 & 646 & 49.4 & 62 & 4.7 & 68 & 5.2 \\
\hline 7 & $\begin{array}{l}\text { BridgeIT mobile application is easy } \\
\text { to use for learning mathematics }\end{array}$ & 572 & 43.8 & 700 & 53.6 & 19 & 1.5 & 16 & 1.2 \\
\hline 8 & $\begin{array}{l}\text { The use of BridgeIT mobile application } \\
\text { will } \\
\text { make many pupils to pass mathematics }\end{array}$ & 453 & 34.7 & 618 & 47.3 & 141 & 10.8 & 95 & 7.3 \\
\hline 9 & $\begin{array}{l}\text { The BridgeIT mobile application } \\
\text { makes me angry when teacher is } \\
\text { charging and using it to teach } \\
\text { mathematics }\end{array}$ & 132 & 10.1 & 181 & 13.8 & 460 & 35.2 & 534 & 40.9 \\
\hline 10 & $\begin{array}{l}\text { When the teacher uses BridgeIT } \\
\text { mobile application for teaching } \\
\text { mathematics, it makes it difficult for } \\
\text { pupils to move around the classroom }\end{array}$ & 301 & 23.0 & 357 & 27.3 & 291 & 22.3 & 358 & 27.4 \\
\hline 11 & $\begin{array}{l}\text { The use of BridgeIT mobile } \\
\text { application for teaching mathematics } \\
\text { by my teacher saves time and effort }\end{array}$ & 553 & 42.3 & 671 & 51.3 & 39 & 3.0 & 44 & 3.4 \\
\hline 12 & $\begin{array}{l}\text { Teacher talks less when using } \\
\text { BridgeIT mobile application to teach } \\
\text { mathematics, hence I concentrate } \\
\text { better in the class }\end{array}$ & 561 & 42.9 & 682 & 52.2 & 31 & 2.4 & 33 & 2.5 \\
\hline 13 & $\begin{array}{l}\text { Learning mathematics through the } \\
\text { use of BridgeIT mobile application } \\
\text { has been a pleasant experience }\end{array}$ & 504 & 38.6 & 631 & 48.3 & 89 & 6.8 & 83 & 6.4 \\
\hline 14 & $\begin{array}{l}\text { Pupils concentrate more in learning } \\
\text { mathematics when BridgeIT mobile } \\
\text { application is used compared to } \\
\text { use of social media }\end{array}$ & 554 & 42.4 & 669 & 51.2 & 49 & 3.7 & 35 & 2.7 \\
\hline 15 & $\begin{array}{l}\text { I do not want to associate with } \\
\text { BridgeIT mobile application because it } \\
\text { diverts my attention away from the class }\end{array}$ & 32 & 2.4 & 63 & 4.8 & 560 & 42.8 & 652 & 49.9 \\
\hline 16 & $\begin{array}{l}\text { I am afraid of BridgeIT mobile } \\
\text { application equipment when installed }\end{array}$ & 51 & 3.9 & 80 & 6.1 & 541 & 41.4 & 635 & 48.6 \\
\hline 17 & $\begin{array}{l}\text { I learn more and better mathematics } \\
\text { from BridgeIT mobile application } \\
\text { than I do from textbooks }\end{array}$ & 519 & 39.7 & 615 & 47.1 & 73 & 5.6 & 100 & 7.7 \\
\hline
\end{tabular}


Hypothesis 1: There is no significant difference in the attitude of pupils on the use of BridgeIT mobile application for teaching mathematics based on their gender.

Table 3 shows the results of Mann-Whitney U test for the attitude of pupils on the use of BridgeIT mobile application for teaching mathematics based on their gender. This showed a difference which is not statistically significant $(\mathrm{Z}=-0.723 ; \mathrm{p}=.470>.05)$. The rank average of the attitude of boys on the use of BridgeIT mobile application based on their gender for teaching mathematics was 646.04, while that of the girls was 660.76. The rank averages of the boys and girls indicated that the attitude of pupils on the use of BridgeIT mobile application based on their gender for teaching mathematics is higher for girls than that of the boys. Since the difference is insignificant, it showed that the difference observed in the attitude of pupils on the use of BridgeIT mobile application based on their gender for teaching mathematics may be due to sampling error as it cannot be generalised.

Table 3

The Mann-Whitney U test computation of male and female pupils' attitude on the use of BridgeIT mobile application for teaching mathematics

\begin{tabular}{llllll}
\hline Gender & $\mathrm{N}$ & $\begin{array}{l}\text { Rank } \\
\text { Average }\end{array}$ & $\begin{array}{l}\text { Sum of } \\
\text { Ranks }\end{array}$ & $\mathrm{U}$ & $\mathrm{Z}$ \\
\hline Male & 600 & 646.04 & 387623.00 & & $\mathrm{P}$ \\
& & & & 207323.00 & -0.72 \\
Female & 707 & 660.76 & 467155.00 & & \\
\hline
\end{tabular}

\section{DISCUSSION}

The attitude of the basic school pupils was examined. The results showed that the responses of the respondents have a positive attitude towards the use of BridgeIT mobile application for learning mathematics. It implies that Nigeria pupils have positive change of attitude when learning mathematics using mobile application. This research finding was corroborated with the finding of Al-Takhyneh (2018) which revealed that the attitude of students towards the use of mobile applications in teaching and learning mathematics was highly positive. Odogwu and Mbah (2015) also agreed that the students showed positive attitudes towards the use of technology application to learning mathematics. However, the findings of this study that if BridgeIT mobile application is integrated into the learning of mathematics at the basic school level, the pupils understanding of mathematics will be greatly achieved, and their performance in mathematics will improve.

The influence of basic school pupils' gender on their attitudes towards using BridgeIT mobile application by the teachers for learning mathematics was also examined in this study. The result indicated that there seems to be no variation in responses of male and female pupils on the various items. That is, gender does not influence the attitude of the basic school pupils towards the use of BridgeIT mobile application by the teachers for learning mathematics.

The result on gender is in line with the result of Badmus (2013) which indicated that no significant difference on the attitude of male and female students that were exposed to Web Quest on Educational Technology Concepts. However, the result contradicted the findings of Chen and Tsai (2005) who reported that male exhibited more favourable attitudes towards web-based learning than the females. Therefore, gender should not be used as a variable that influences the basic school pupils' attitude towards using BridgeIT mobile application for learning mathematics by their teachers.

\section{CONCLUSION}

The findings of this study indicated that 
1. pupils' attitude towards using BridgeIT mobile application for learning mathematics change their understanding in mathematics, and the pupils are likely to perform better in mathematics whenever they learn using BridgeIT mobile application.

2. gender does not influence the attitude of the basic school pupils towards using BridgeIT mobile application by their teachers.

\section{RECOMMENDATIONS}

Based on the findings of this study, the following recommendations were made:

1. Basic school pupils should be exposed to various technologies for academic improvement in Mathematics, because it enhanced pupils understanding of mathematics at basic school level of education.

2. Lagos State Government should extend the use of BridgeIT mobile application to other basic schools in the State.

3. Federal and State Ministry of Education should look into the integration of BridgeIT mobile application in basic school education as innovation.

\section{REFERENCES}

Abdulhamid, M. G., Abubakar, M., \& Tela, A. B. (2017). Cluster schools model of teachers professional development: Role on pupils active participation in mathematics class in Gombe State. Abacus: The Journal of the Mathematical Association of Nigeria, 42(2), 143-148.

Akanmu, I. A. (2017). Integration of geogebra software into teaching and learning of mathematics in Nigeria senior secondary schools. Abacus: The Journal of the Mathematical Association of Nigeria, $42(1), 1-11$.

Al-Takhyneh, B. (2018). Attitudes towards using mobile applications in teaching mathematics in Open learning systems. International Journal of E-Learning \& Distance Education, 33(1), 1-15.

Ayotola, A., \& Ishola, .S. (2013). Preparation of primary teachers in pupil-centered Activity based mathematics instructions and its model. Proceeding of $1^{\text {st }}$ Annual International Inter Disciplinary Conference ALK 2013, 24-26 April, Azores Portugal.

Badmus, A. M. (2013). Development and evaluation of a Web-Quest application on educational technology concepts for undergraduate students in Nigeria (Unpublished Doctoral Dissertation). University of Ilorin, Ilorin, Nigeria.

British Educational Communication and Technology Agency (BECTA) (2003). What the research says about Using ICT in Maths. www.bacta.org.uk/research

Chen, R. S., \& Tsai, C. C. (2005). Gender differences in Taiwan University students toward the webbased learning. In Lool, C.K., Jonassen, M., \& Ikeda, M. (Eds). International Conference of Computers in Education, 133, 629-632.

Cherry,K. (2015). Attitude. Retrieved from psychology.about.com/od/socialpsychology/a/at on $14 / 4 / 16$

Etuk, N. E., Maria, E. A., \& Asukwo, O. U. (2013). Students perception of teach characteristics and their attitude towards mathematics in Ovon Education Zone, Nigeria. International Education Studies, 6(2), 197-204. 
Graff, M. (2003). Cognitive style and attitudes towards using online learning and assessment methods. Electronic Journal of E-learning, 1, 21-28.

Haunsel, P. B., \& Hill, R. S. (2002). The micro computer and achievement and attitudes in high school biology. Journal Research Science Teaching 19898; 26:543-549.

Imoko, B. I., \& Isa, S. A. (2015). Impact of computer Genues on pupils achievement in mathematics in primary achievement in mathematics in primary school in Lafia Local Government Area: A tool for technological development. Proceedings of September 2015 Annual National Conference of the mathematical Association of Nigeria 63-71.

International Youth Foundation (2011). Bridge IT (elimukwa Teknologia). Summative evaluation July 2011, USA. Retrieved on $25^{\text {th }}$ February 2015 from www.iyfnet.org.

LASUBEB (2015). Report on BridgeIT Programme: A quarterly report for the month of JanuaryApril, 2015. School Support Service Department of Lagos State Universal Basic Education Board (LASUBEB)

Maio, G., \& Haddock, G. (2010). The psychology of attitude and attitude change. London: AGE Publications Ltd.

Malik, N. A. (2017). Perceptions of teachers and pupils on use of BridgeIT mobile application for teaching mathematics in Lagos State, Nigeria (Unpublished doctoral dissertation). University of Ilorin, Ilorin, Nigeria.

Malik, N. A., \& Salman, M. F. (2016). Effect of BridgeIT mobile application on middle basic school pupils' performance in mathematics in Lagos State. Abacus: The Journal of the Mathematical Association of Nigeria, 41(1), 86-92.

Malik, N. A., \& Salman, M. F. (2018). Teachers perceptions of the use of BridgeIT mobile application for teaching mathematics at basic schools in Lagos State, Nigeria. ABACUS: The Journal of the Mathematical Association of Nigeria, 43(1), 25-40.

National Open University of Nigeria (2012). Primary mathematics curriculum and methods. Course guide for PED144, Lagos.

National Teachers' Institute (2000). National Certificate in Education Course Book on Primary Education Studies for PES 242. National Teachers' Institute, Kaduna, Nigeria.

Nayashi, A., Chen, C., Ryan, T., \& Wu, J. (2004). The role of social presence and moderating role of computer self-efficacy in predicting the continuous usage of e-learning systems. Journal of Information systems Education, 15(2), 134-154.

Neo, M. (2003). Developing a collaborative learning environment using a web-based design. Journal of Computer Assisted Learning 19, 462-473.

Nneji, S. O., \& Alio, B. C. (2017). Effect of use of computer animations strategy on secondary school students' achievement and retention in algebra in Enugu State. Abacus: The Journal of the Mathematical Association of Nigeria, 42(1), 12-21.

Odogwu, H. N., \& Mbah, S. (2015). Attitude and Competence of mathematics teachers to the information and communication technology (ICT) Use. Proceedings of September 2015 Annual National Conference of the Mathematics Association of Nigeria, 16-27.

Olive, J., \& Makar, K. (2010). Using technology to support effective mathematics teaching and learning: What counts? 17th ICMI Study on Mathematics Education and Technology, 67-70. 
Pearson Foundation (2011b). BridgeIT Lagos State Teacher's Guide. Lagos: Nigeria. Pearson Foundation.

Pearson Foundation (2012). Summative Evaluation of the NOKIA \& Pearson Foundation BridgeIT India Project Year 1 2011-2012 School Year. BridegIT India 2011-2012 Endline Report.

Pearson Foundation (2014). Developing teaches through mobile technology. Overview on BridgeIT 10- year-report.

Rhoda, C., \& Gerald, K. (2000). Internal Consistency Reliabilities for 14 computers. Attitude Scale. Journal of Education Technology, 8(4), 327-336.

Saade, R., \& Galloway, I. (2005). Understanding the acceptance of multimedia applications for learning. Issues in informing Science and Information Technology, 2, 287-296.

Salman, M. F. (2009). Active Learning Techniques (ALT) in mathematics workshop: Nigerian primary school teachers' assessment. International Electronic Journal of Mathematics Education. 4(1), 23-35.

Wafa', N. M., \& Awatif, M. A. (2009). University students' Attitude towards cell phone learning environment. Proceeding of ICL conference September 23-24, 2009, 568-578 villach, Austria.

Wheeler, S., Waite, S. J., \& Bromfield, C. (2002). Promoting creative thinking through the use of ICT. Journal of computer assisted learning, 18, 367-378.

Williams, J. (2003). Computers and project-based learning. Media and Methods Magazine. Retrieved on $15^{\text {th }}$ July 2014 from www.media-methods.com 